Research Article

\title{
Trends in Gender Authorship and Collaborations: A 30-Year Comparative Bibliometric Analysis of Manuscripts from The Journal of Bone and Joint Surgery and The Bone and Joint Journal
}

\author{
Maria E. Squire $\left(\mathbb{D},{ }^{1}\right.$ Katherine Schultz $\left(\mathbb{D},{ }^{2}\right.$ Donnell McDonald $\left(\mathbb{D},{ }^{2}\right.$ Cory Meixner $\left(\mathbb{D},{ }^{2}\right.$ \\ Dayton Snyder $\mathbb{D}^{2},{ }^{2}$ Alyssa M. Cooke $\left(\mathbb{D},{ }^{2}\right.$ Jacob C. Davis $\mathbb{D}^{2},{ }^{2}$ Sarina Masso Maldonado $\mathbb{D}^{2}$ \\ Carlos R. Martinez Licha $\mathbb{D}^{2},{ }^{2}$ Elizabeth C. Whipple $\mathbb{D D}^{3}{ }^{3}$ Melissa A. Kacena $\mathbb{D}^{2}{ }^{2}$ \\ and Randall T. Loder $\mathbb{D}^{2}$
}

${ }^{1}$ University of Scranton, Department of Biology, Scranton, PA, USA

${ }^{2}$ Indiana University School of Medicine, Department of Orthopaedic Surgery, Indianapolis, IN, USA

${ }^{3}$ Ruth Lilly Medical Library, Indiana University School of Medicine, Indianapolis, IN, USA

Correspondence should be addressed to Randall T. Loder; rloder@iupui.edu

Received 1 June 2020; Revised 2 November 2020; Accepted 3 December 2020; Published 18 December 2020

Academic Editor: Mark E. Shaffrey

Copyright (C) 2020 Maria E. Squire et al. This is an open access article distributed under the Creative Commons Attribution License, which permits unrestricted use, distribution, and reproduction in any medium, provided the original work is properly cited.

\begin{abstract}
Publishing original peer-reviewed research is essential for advancement through all career stages. Fewer women than men hold seniorlevel positions in academic medicine and, therefore, examining publication trends relative to gender is important. The goal of this study was to examine and compare publication trends in The Journal of Bone and Joint Surgery (JBJS) and The Bone and Joint Journal (BJJ) with a particular emphasis on trends regarding author gender. Data was collected and analyzed for manuscripts published in JBJS and BJJ over the past 30 years. For manuscripts published in 1986, 1996, 2006, and 2016, we recorded the numbers of authors, manuscript pages, references, collaborating institutions, the position in the byline of the corresponding author, the country of the corresponding author, and the names of the first and corresponding author. We also calculated the normalized number of citations and corresponding author position. The number of authors, institutions, and countries collaborating on manuscripts published in both JBJS and BJJ increased over time. JBJS published more manuscripts from North America and BJJ published more manuscripts from Europe. In both journals, the percentage of women as first and/or corresponding author increased over time. Trends over the past 30 years have shown increased collaborations with greater citations in manuscripts published in JBJS and BJJ. In the same time period, both journals demonstrated a rise in the percentage of manuscripts with women first and/or corresponding authors, suggesting a decrease in the gender gap.
\end{abstract}

\section{Introduction}

Original research in peer-reviewed journals allows the review and dissemination of new information. The increasing complexity of research has resulted in increased collaboration among researchers (same institution or geographic region, or different countries) to obtain appropriate expertise [1-3]. Collaboration is easier with the advances in technology [3]. Studies have suggested that international collaborations expand the dissemination of information, increasing readership and citations [1, 4]. Increasing collaboration may also be due to the "publish or perish" paradigm [5-9], as publication production is important at all career stages [9-11].

Medicine has traditionally been a field dominated by men, although women have made significant gains; in 20182019 , women represented $49.5 \%$ of US medical school matriculates [12]. Due to a few senior-level women in academic medicine, it is important to examine publication trends relative to gender. In the USA, there has been no meaningful change in orthopedic surgery residents from $10.9 \%$ in 2006 to $14.4 \%$ in 2015 [13]. This minimal change 
likely reflects the minimal change in the percentage of women graduates in US medical schools, $41.5 \%$ in 2006 and $47.4 \%$ in 2016 [14]. In the UK, women comprised $25 \%$ of orthopedic trainees and only $5 \%$ of all orthopedic surgery consultants in 2014 [15]. In spite of attempts to close the gender gap [16], women still lag behind men. The goals of this study were twofold: (1) to examine publication trends in The Journal of Bone and Joint Surgery (JBJS) and The Bone and Joint Journal (BJJ) in bibliometric variables over time and (2) specifically to study author gender trends. These two journals were chosen as they are well-known orthopedic surgery journals covering material from all orthopedic subspecialties and highly regarded in both the English and non-English speaking world. As JBJS is a US-based journal and BJJ a UK-based journal, it also allows for studying author gender trends between the USA and UK. Such data will be helpful for trainees, junior faculty, and senior faculty in mentorship positions.

\section{Materials and Methods}

Manuscripts published in JBJS and BJJ over the past 30 years were analyzed using a well-established method [17]. Data was collected for 1986, 1996, 2006, and 2016. Excluded from the analysis were editorials, memorandums, letters, commentaries, and case reports. The number of authors, manuscript pages, references, and collaborating institutions, corresponding author position (CAP) in the byline, country of the corresponding author, and names of the first and corresponding author were collected. A Scopus search performed in December of 2017 determined the number of times each manuscript had been cited and was normalized by dividing by the age of the manuscript in years. The CAP was standardized by dividing by the total number of authors on the manuscript. The corresponding author's geographical location was categorized into regions: Asia, Australia/New Zealand, Europe, Latin America, and North America.

The first and corresponding author gender was determined using the "Baby Name Guesser" software of Geoff Peters' (http://www.gpeters.com/names/baby-names.php). The "Baby Name Guesser" website produces a gender and gender ratio for first names. This method was previously used in several bibliometric studies from our group [17-26] as well as others in both medicine [27-31] and other disciplines [32, 33]. For a ratio 23.0 , the gender given was assumed correct. If below 3.0, the gender was manually verified using a Google search. If no gender could be ascertained, then the manuscript was excluded from gender analyses.

2.1. Statistical Analyses. Discrete data are reported as frequencies and percentages and continuous data as the mean \pm 1 standard deviation. Differences in categorical data were analyzed using Fisher's exact test $(2 \times 2$ tables $)$ or Pearson's $\chi 2$ test $(>2 \times 2$ tables). Nonparametric tests were used to analyze differences in continuous data due to nonnormal distributions (Mann-Whitney $U$ for 2 groups; Kruskal-Wallis test for 3 or more groups). Observed trends over the 10-year intervals were analyzed using the Cochran linear trend test. Statistical analyses were performed with Systat 10 software $^{\mathrm{TM}}$ (Systat Software, Chicago, IL, 2000) with a significance level of 0.05 .

\section{Results}

3.1. Cross-Journal Analysis. There were 989 JBJS and 893 BJJ manuscripts; JBJS manuscripts had more authors $(4.6 \pm 2.3$ vs. $4.3 \pm 2.1, p=0.005)$, references $(30.5 \pm 22.1$ vs. $25.7 \pm 18.0$, $\left.p<10^{-6}\right)$, printed pages $\left(8.0 \pm 2.8\right.$ vs. $\left.5.5 \pm 2.0, p<10^{-6}\right)$, and normalized citations $\left(4.56 \pm 5.29\right.$ vs. $\left.3.07 \pm 2.46, p<10^{-6}\right)$ than BJJ manuscripts. There were no differences between journals for standardized CAP $(0.43 \pm 0.32$ vs. $0.43 \pm 0.30$, $p=0.10)$, the number of collaborating institutions $(2.2 \pm 1.9$ vs. $2.0 \pm 1.4, p=0.65)$, countries (1.2 \pm 0.6 vs. $1.2 \pm 0.5$, $p=0.20$ ), or single author manuscripts (49 vs. $55, p=0.27$ ).

3.2. Analyses by Region. The regions were known for 987 $J B J S$ and $882 B J J$ manuscripts. For JBJS, the manuscripts came from North America $(n=758)$, Europe $(n=158)$, Asia $(n=61)$, and Australia/New Zealand $(n=10)$. For BJJ, the manuscripts came from Europe $(n=587)$, North America $(n=128)$, Asia $(n=118)$, and Australia/New Zealand $(n=49)$.

For JBJS (Table 1), manuscripts with the greatest number of authors came from Australia/New Zealand $(5.8 \pm 2.6)$ and the least from North America $(4.4 \pm 2.4)$. For BJJ, manuscripts with the greatest number of authors came from Asia $(4.8 \pm 1.9)$ and the least from Australia/New Zealand $(4.2 \pm 1.9)$. Manuscripts with the greatest standardized CAP, for both JBJS and BJJ, came from Australia/New Zealand $(0.56 \pm 0.43$ and $0.54 \pm 0.35)$ followed by North America $(0.45 \pm 0.33$ and $0.50 \pm 0.32)$. For JBJS, the lowest standardized CAP was for manuscripts from Europe $(0.37 \pm 0.30)$ whereas for $B J J$ it was the lowest for those from Asia $(0.41 \pm 0.30)$. There was a difference for JBJS in the number of collaborating countries between North America $(1.1 \pm 0.5)$, Europe $(1.4 \pm 1.0)$, Asia $(1.1 \pm 0.2)$, and Australia/ New Zealand $(1.7 \pm 0.7)$, but there was no difference for BJJ. There were no statistically significant differences in the number of institutions or printed pages. There were no differences in the number of normalized citations for JBJS; there was a difference for $B J J$ with the highest from North

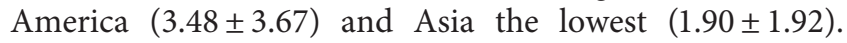
There were no regional differences in the number of references for JBJS; in BJJ, the most came from North America $(30.5 \pm 17.1)$, and the least from Europe $(24.8 \pm 18.6)$.

3.3. Analyses Over Time by Journal. The number of manuscripts published increased from 1986 to 2006 before declining in 2016. For JBJS, there were 154 in 1986, 159 in 1996, 400 in 2006, and 276 in 2016. For BJJ, there were 159 in 1986, 178 in 1996, 298 in 2006, and 258 in 2016. The number of single-authored manuscripts in JBJS did not show a significant change $(p=0.17)$ but declined in BJJ $\left(p<10^{-6}\right)$ (Figure 1(a)). The number of authors increased significantly in both JBJS $\left(p<10^{-6}\right)$ and BJJ $\left(p<10^{-6}\right)$ (Figure $\left.1(\mathrm{~b})\right)$. The 
TABLE 1: Bibliometric analyses by journal and geographical region.

\begin{tabular}{|c|c|c|c|c|c|c|c|c|c|c|}
\hline & \multicolumn{5}{|c|}{$J B J S$} & \multicolumn{5}{|c|}{$B J J$} \\
\hline & $\begin{array}{c}\text { North } \\
\text { America } \\
(n=758)\end{array}$ & $\begin{array}{c}\text { Europe } \\
(n=158)\end{array}$ & $\begin{array}{c}\text { Asia } \\
(n=61)\end{array}$ & $\begin{array}{l}\text { Australia/ } \\
\text { New } \\
\text { Zealand } \\
(n=10)\end{array}$ & $p$ value & $\begin{array}{c}\text { North } \\
\text { America } \\
(n=128)\end{array}$ & $\begin{array}{c}\text { Europe } \\
(n=587)\end{array}$ & $\begin{array}{c}\text { Asia } \\
(n=118)\end{array}$ & $\begin{array}{l}\text { Australia/ } \\
\text { New } \\
\text { Zealand } \\
(n=49)\end{array}$ & $\begin{array}{c}p \\
\text { value }\end{array}$ \\
\hline Author no. & $4.4 \pm 2.4$ & $4.9 \pm 2.4$ & $5.4 \pm 1.7$ & $5.8 \pm 2.6$ & 0.000009 & $4.3 \pm 2.1$ & $4.2 \pm 2.1$ & $4.8 \pm 1.9$ & $4.2 \pm 1.9$ & 0.004 \\
\hline $\begin{array}{l}\text { No. of } \\
\text { institutions }\end{array}$ & $2.2 \pm 1.9$ & $2.3 \pm 2.0$ & $2.1 \pm 1.3$ & $3.5 \pm 2.8$ & 0.28 & $2.1 \pm 1.4$ & $2.9 \pm 1.4$ & $1.9 \pm 1.2$ & $2.2 \pm 1.5$ & 0.44 \\
\hline No. of countries & $1.1 \pm 0.5$ & $1.4 \pm 1.0$ & $1.1 \pm 0.2$ & $1.7 \pm 0.7$ & $<10^{-6}$ & $1.2 \pm 0.5$ & $1.2 \pm 0.5$ & $1.1 \pm 0.3$ & $1.2 \pm 0.5$ & 0.072 \\
\hline $\begin{array}{l}\text { No. of citations } \\
\text { (normalized) }\end{array}$ & $4.44 \pm 5.04$ & $5.67 \pm 6.67$ & $3.18 \pm 3.51$ & $4.67 \pm 5.53$ & 0.083 & $3.48 \pm 3.67$ & $3.20 \pm 3.63$ & $1.90 \pm 1.92$ & $3.49 \pm 3.47$ & 0.0003 \\
\hline No. of references & $31.0 \pm 23.6$ & $30.5 \pm 16.8$ & $24.7 \pm 11.3$ & $34.6 \pm 24.2$ & 0.24 & $30.5 \pm 17.1$ & $24.8 \pm 18.6$ & $25.3 \pm 16.3$ & $26.5 \pm 16.2$ & 0.0001 \\
\hline No. of pages & $7.9 \pm 3.0$ & $7.9 \pm 2.4$ & $7.8 \pm 2.2$ & $9.4 \pm 0.8$ & 0.15 & $5.5 \pm 1.7$ & $5.4 \pm 2.0$ & $5.7 \pm 1.9$ & $5.7 \pm 2.0$ & 0.28 \\
\hline $\begin{array}{l}\text { Corresponding } \\
\text { author position } \\
\text { (standardized) }\end{array}$ & $0.45 \pm 0.33$ & $0.37 \pm 0.30$ & $0.40 \pm 0.32$ & $0.56 \pm 0.43$ & 0.046 & $0.50 \pm 0.32$ & $0.42 \pm 0.29$ & $0.41 \pm 0.30$ & $0.54 \pm 0.35$ & 0.009 \\
\hline
\end{tabular}

Values are mean \pm 1 standard deviation.

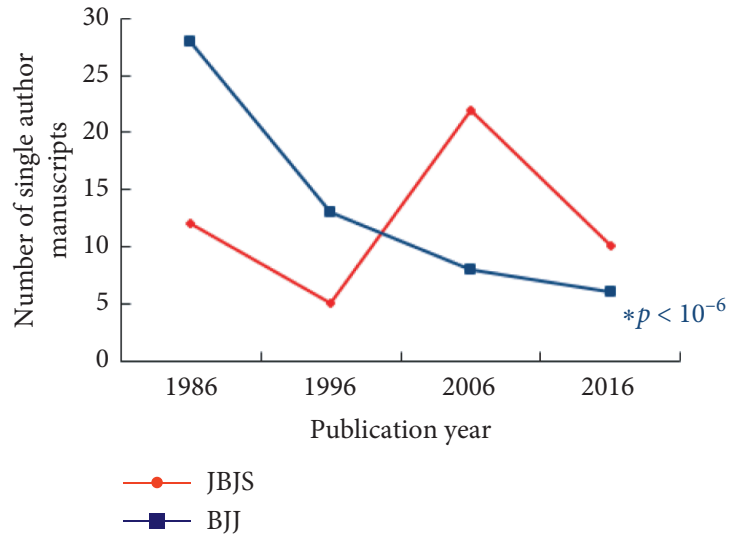

(a)

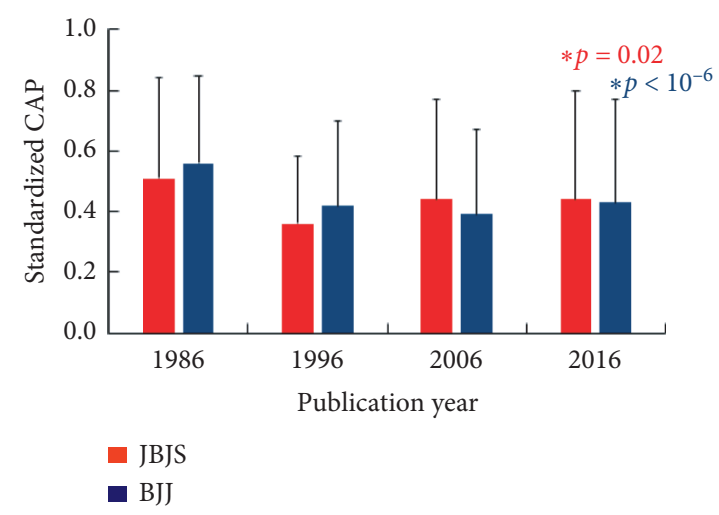

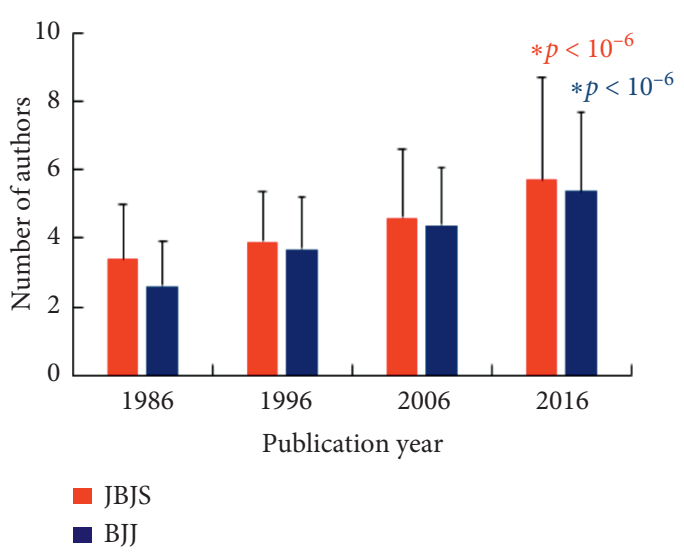

(b)

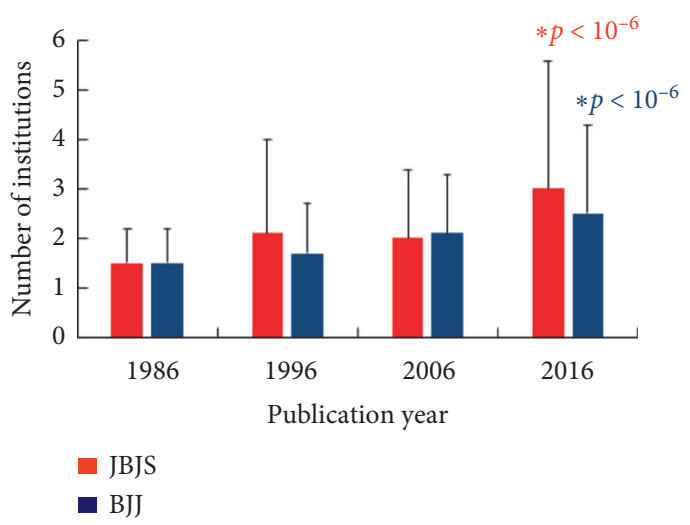

(d)

FIgURE 1: Continued. 


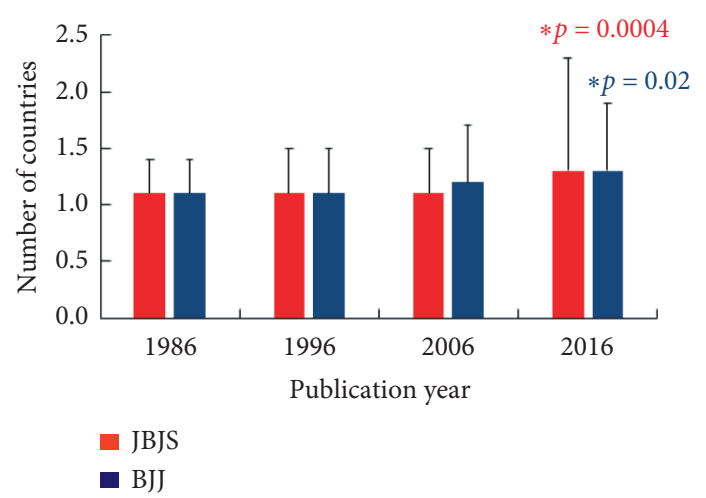

(e)

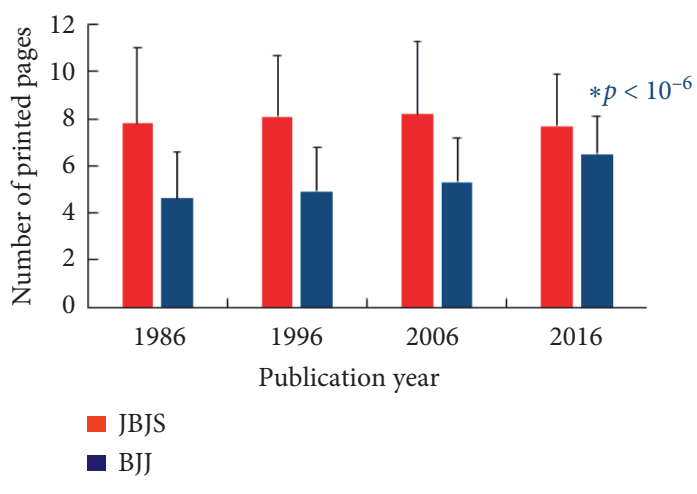

(g)

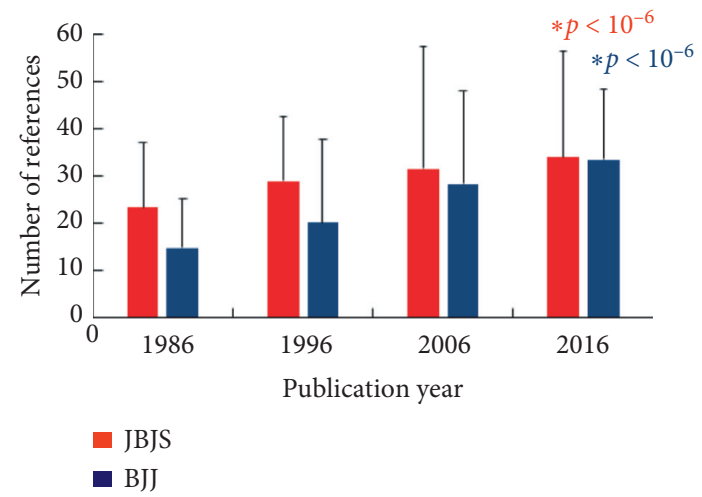

(f)

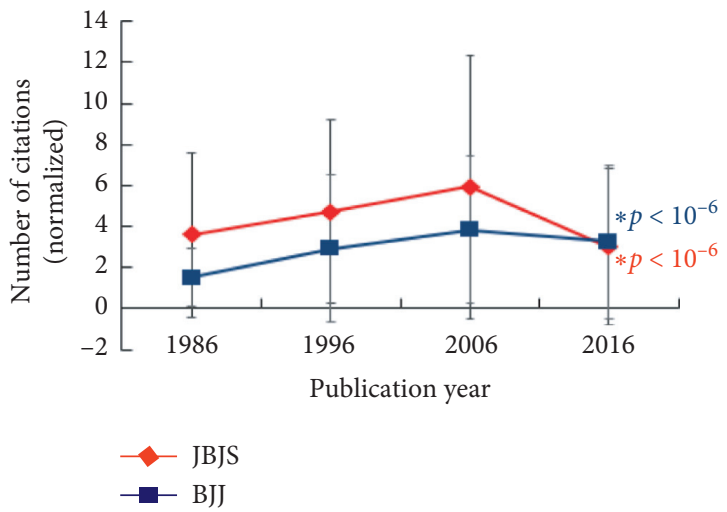

(h)

FIGURE 1: Analyses by geographic region over time for JBJS and BJ for (a) the number of single author manuscripts, (b) number of authors over time in JBJS and BJJ, (c) standardized corresponding author position (CAP), (d) number of collaborating institutions, (e) number of countries, (f) number of references, (g) number of printed pages, and (h) number of normalized citations. The asterisks represent those having statistically significant differences over the four decades as assessed by the Cochran linear trend test.

standardized CAP changed over time for both JBJS $(p=0.02)$ and $B J J\left(p<10^{-6}\right)$ (Figure $\left.1(\mathrm{c})\right)$. The number of collaborating institutions increased significantly in JBJS $\left(p<10^{-6}\right)$ and BJJ $\left(p<10^{-6}\right)$ (Figure $1(\mathrm{~d})$ ) as did the number of countries for JBJS $(p=0.0004)$ and BJJ $(p=0.02)$ (Figure 1(e)). For both journals, the number of references increased from 1986 to $2016\left(p<10^{-6}\right)$ (Figure 1(f)). While the number of printed pages did not change in JBJS $(p=0.30)$, there was a $41 \%$ increase in the number of printed pages from 1986 to 2016 in $B J J\left(p<10^{-6}\right)$ (Figure $\left.1(\mathrm{~g})\right)$. The number of normalized citations increased in JBJS from $3.6 \pm 4.0$ in 1986 to $5.9 \pm 6.4$ in 2006 and then decreased to $3.0 \pm 3.8$ in $2016\left(p<10^{-6}\right)$ (Figure 1(h)); for BJJ, it increased from $1.5 \pm 1.4$ in 1986 to $3.9 \pm 3.6$ in 2006 and then decreased to $3.3 \pm 3.8$ in 2016 $\left(p<10^{-6}\right.$ ) (Figure $1(\mathrm{~h})$ ).

3.4. Analyses by Gender. First author gender was available for $97.0 \%$ of JBJS and $90.6 \%$ of BJJ manuscripts. For JBJS, $11.5 \%$ of first authors were women and $10.6 \%$ for $B J J$ $(p=0.60)$. Corresponding author gender was available for $84.7 \%$ of JBJS and $93.2 \%$ of BJJ manuscripts. In JBJS, $10.9 \%$ of the corresponding authors were women and $9.1 \%$ for $B J J$ $(p=0.25)$.
There were no differences by first author gender (Table 2) in JBJS for the numbers of authors, institutions, collaborating countries, normalized citations, references, printed pages, or standardized CAP. The findings were the same in $B J J$ except for the number of printed pages; manuscripts with women first authors were longer $(6.4 \pm 2.2)$ than those with men first authors $(5.4 \pm 1.9)$.

There were no differences by corresponding author gender (Table 3 ) for the numbers of authors, institutions, collaborating countries, normalized citations, references, printed pages, or standardized CAP for JBJS. Findings were the same for $B J J$, except for the number of references and printed pages. $B J J$ manuscripts with women corresponding authors were longer $(6.3 \pm 2.2)$ than those with men corresponding authors $(5.4 \pm 1.9)$ with more references $(29.6 \pm 17.6,25.8 \pm 17.8)$.

3.5. Analyses by Gender across Regions. The percentage of women first authors in JBJS manuscripts for all four decades varied by region with Australia/New Zealand having the most (30\%), then Europe (13\%), North America (11.6\%), and Asia $(2 \%)(p=0.046)$. The percentage of manuscripts with women first authors in $B J J$ did not vary by region (Australia/ 
TABLE 2: Bibliometric analyses by journal and first author gender.

\begin{tabular}{|c|c|c|c|c|c|c|}
\hline & \multicolumn{3}{|c|}{$J B J S$} & \multicolumn{3}{|c|}{$B J J$} \\
\hline & Woman & Man & $p$ value & Woman & Man & $p$ value \\
\hline Author number & $4.7 \pm 2.5$ & $4.6 \pm 2.3$ & 0.81 & $4.7 \pm 2.1$ & $4.3 \pm 2.1$ & 0.11 \\
\hline Number of institutions & $2.3 \pm 1.6$ & $2.2 \pm 1.9$ & 0.12 & $2.3 \pm 1.4$ & $2.0 \pm 1.4$ & 0.21 \\
\hline Number of countries & $1.2 \pm 0.5$ & $1.2 \pm 0.6$ & 0.38 & $1.2 \pm 0.4$ & $1.2 \pm 0.5$ & 0.47 \\
\hline Number of citations (normalized) & $5.07 \pm 4.86$ & $4.53 \pm 5.34$ & 0.073 & $4.01 \pm 4.86$ & $3.09 \pm 3.28$ & 0.18 \\
\hline Number of references & $30.4 \pm 18.7$ & $30.4 \pm 22.6$ & 0.61 & $28.6 \pm 16.6$ & $26.2 \pm 18.2$ & 0.08 \\
\hline Number of pages & $7.8 \pm 2.5$ & $8.0 \pm 2.9$ & 0.57 & $6.4 \pm 2.2$ & $5.4 \pm 1.9$ & 0.00012 \\
\hline Corresponding author position (standardized) & $0.45 \pm 0.34$ & $0.43 \pm 0.32$ & 0.69 & $0.45 \pm 0.31$ & $0.41 \pm 0.29$ & 0.59 \\
\hline
\end{tabular}

Values are mean \pm 1 standard deviation.

TABLE 3: Bibliometric analyses by journal and corresponding author gender.

\begin{tabular}{|c|c|c|c|c|c|c|}
\hline & \multicolumn{3}{|c|}{$J B J S$} & \multicolumn{3}{|c|}{$B J J$} \\
\hline & Woman & Man & $p$ value & Woman & Man & $p$ value \\
\hline Author number & $4.8 \pm 2.2$ & $4.6 \pm 2.3$ & 0.53 & $4.7 \pm 2.2$ & $4.3 \pm 2.1$ & 0.14 \\
\hline Number of institutions & $2.3 \pm 1.5$ & $2.3 \pm 2.0$ & 0.26 & $2.2 \pm 1.5$ & $2.0 \pm 1.4$ & 0.60 \\
\hline Number of countries & $1.1 \pm 0.4$ & $1.2 \pm 0.7$ & 0.56 & $1.1 \pm 0.3$ & $1.2 \pm 0.5$ & 0.097 \\
\hline Number of citations (normalized) & $4.87 \pm 5.04$ & $4.74 \pm 5.51$ & 0.71 & $3.52 \pm 3.64$ & $3.16 \pm 3.53$ & 0.56 \\
\hline Number of references & $29.9 \pm 15.9$ & $31.1 \pm 22.8$ & 0.89 & $29.6 \pm 17.6$ & $25.8 \pm 17.8$ & 0.02 \\
\hline Number of pages & $7.8 \pm 2.3$ & $8.0 \pm 2.9$ & 0.60 & $6.3 \pm 2.2$ & $5.4 \pm 1.9$ & 0.0007 \\
\hline Corresponding author position (standardized) & $0.39 \pm 0.29$ & $0.44 \pm 0.33$ & 0.20 & $0.39 \pm 0.29$ & $0.43 \pm 0.31$ & 0.18 \\
\hline
\end{tabular}

Values are mean \pm 1 standard deviation.

New Zealand (13\%), Europe (11.4\%), Asia (8.4\%), and North America $(8.1 \%)(p=0.60))$.

3.6. Analyses by Gender over Time. The percentage of manuscripts with women first authors increased from $2.0 \%$ to $16.1 \%$ in JBJS ( $p=0.00001)$ and from $6.3 \%$ to $15.3 \%$ in $B J J$ $(p=0.01)$ (Figure 2(a)). The percentage of manuscripts with women corresponding authors increased from $1.4 \%$ to $16.2 \%$ in JBJS ( $p=0.0003)$ and from $6.2 \%$ to $15.2 \%$ in $B J J$ $(p=0.003)$ (Figure 2(b).

We also analyzed differences in author gender over time by region (Table 4). Due to the small number from Australia/New Zealand, those were excluded for JBJS. For $J B J S$, the percentage of manuscripts with women first authors (Figure $3(\mathrm{a})$ ) rose from $2.3 \%$ to $15.3 \%(p=0.0025)$ for those from North America, from $0.0 \%$ to $19.2 \%$ $(p=0.034)$ for those from Europe, and with no significant change in those from Asia. For BJJ, the percentage of manuscripts with women first authors (Figure 3(b)) rose from $6.6 \%$ to $19.6 \%(p=0.013)$ for those from Europe, with no significant changes in those from North America, Australia/New Zealand, or Asia. For JBJS, the percentage of manuscripts with women corresponding authors (Figure 3(c)) rose from $1.7 \%$ to $14.8 \%(p=0.0052)$ for those from North America and $0.0 \%$ to $20.8 \%(p=0.044)$ for those from Europe, with no significant changes for those from Asia. For BJJ, the percentage of manuscripts with women corresponding authors (Figure 3(d)) rose from $0.0 \%$ to $21.2 \%(p=0.015)$ for those from Asia and from $0.0 \%$ to $25.0 \%(p=0.041)$ for those from Australia/ New Zealand, with no significant changes for those from North America or Europe.
3.7. Analyses by Gender across Subspecialties. Manuscripts were categorized by subspecialty into foot and ankle, general, hand, joint arthroplasty, oncology, pediatrics, spine, sports medicine, and trauma (Figure 4). The sports medicine subspecialty was excluded from the analysis due to low numbers (15 from JBJS and one from $B J J)$. Reporting percentages of women first authors relative to the total manuscripts within each subspecialty (Figure 4(a)), the largest percentage of women first authors in JBJS was in pediatrics (22\%) and the lowest in the spine (9\%). In BJJ, the largest percentage of women first authors was in hand (29\%) and the lowest in pediatrics (5\%). These differences between journals were significant $(p=0.002)$. Reporting percentages of women first authors in a subspecialty relative to the total manuscripts across all subspecialties (Figure 4(b)), the largest percentage of women first authors in both journals was in joint arthroplasty ( $42 \%$ for JBJS and $37 \%$ for $B J J)$. The second highest was in pediatrics for JBJS $(16 \%)$ and general for $B J J(25 \%)$; the lowest percentage of women first authors was in hand for JBJS (4\%) and in pediatrics for BJJ $(2 \%)$ $(p=0.0014)$.

3.8. Analyses by Author Gender Combination over Time. Manuscripts were categorized into one of four gender combinations between the first author and corresponding author: WW (women as first and corresponding authors), WM (women as first and men as corresponding authors), MW (men as first and women as corresponding authors), and MM (men as first and corresponding authors). Single author manuscripts and those where the first author was also the corresponding author were excluded from these analyses. There were no significant differences in any of the four 


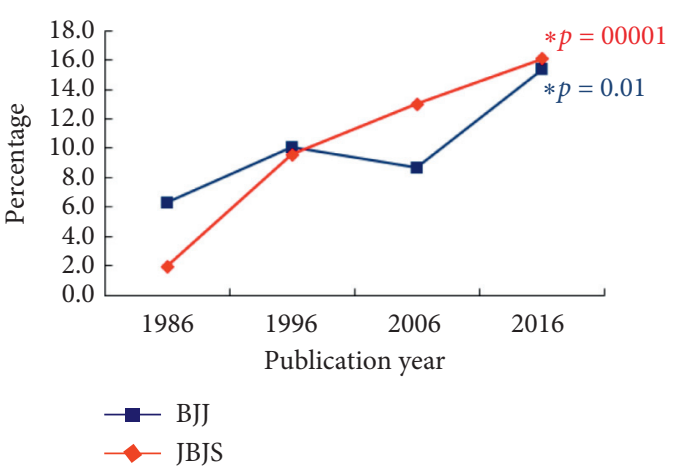

(a)

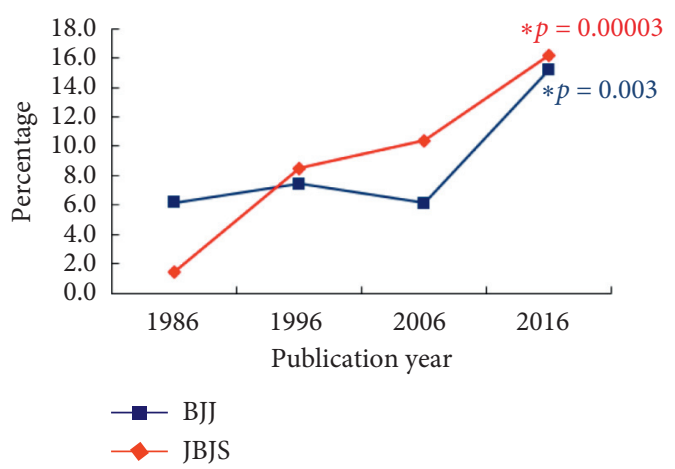

(b)

FIgURE 2: Percentage of women as first (a) or corresponding (b) authors over time in JBJS and BJJ. The asterisks represent those having statistically significant changes over the four decades as assessed by the Cochran linear trend test.

TABLE 4: Bibliometric analyses by author gender, journal, and geographic region over time.

\begin{tabular}{|c|c|c|c|c|c|c|c|c|c|c|c|c|c|c|c|c|c|c|}
\hline & \multicolumn{9}{|c|}{ First author } & \multicolumn{9}{|c|}{ Corresponding author } \\
\hline & \multicolumn{4}{|c|}{$n$} & \multicolumn{4}{|c|}{$\% n$} & \multirow[b]{2}{*}{$p$ value $^{\wedge}$} & \multicolumn{3}{|c|}{$n$} & \multicolumn{4}{|c|}{$\% n$} & \multirow[b]{2}{*}{2016} & \multirow[b]{2}{*}{$p$ value $^{\wedge}$} \\
\hline & 1986 & 1996 & 2006 & 2016 & 1986 & 1996 & 2006 & 2016 & & 1986 & 1996 & 2006 & 2016 & 1986 & 1996 & 2006 & & \\
\hline \multicolumn{19}{|c|}{$J B J S$ and $B J J$} \\
\hline $\begin{array}{l}\text { All } \\
\text { woman }\end{array}$ & 11 & 32 & 74 & 78 & 3.9 & 9.8 & 11.2 & 15.8 & 0.000001 & 9 & 26 & 58 & 74 & 4.5 & 8.0 & 8.7 & 15.8 & 0.000003 \\
\hline $\begin{array}{l}\text { Man } \\
\text { North }\end{array}$ & 268 & 293 & 586 & 415 & 96.1 & 90.2 & 88.8 & 84.2 & & 189 & 301 & 608 & 394 & 95.5 & 92.0 & 91.3 & 84.2 & \\
\hline $\begin{array}{l}\text { America } \\
\text { woman }\end{array}$ & 5 & 14 & 46 & 31 & 3.5 & 9.0 & 14.0 & 12.9 & 0.002 & 3 & 12 & 36 & 30 & 4.1 & 7.8 & 11.0 & 13.7 & 0.01 \\
\hline Man & 138 & 141 & 283 & 210 & 96.5 & 91.0 & 86.0 & 87.1 & & 70 & 141 & 290 & 189 & 95.9 & 92.2 & 89.0 & 86.3 & \\
\hline $\begin{array}{l}\text { Europe } \\
\text { woman }\end{array}$ & 6 & 16 & 22 & 37 & 5.8 & 11.5 & 8.6 & 19.5 & 0.0014 & 6 & 13 & 20 & 31 & 5.9 & 9.1 & 7.6 & 16.7 & 0.005 \\
\hline Man & 98 & 123 & 234 & 153 & 94.2 & 88.5 & 91.4 & 80.5 & & 96 & 130 & 243 & 155 & 94.1 & 90.9 & 92.4 & 83.3 & \\
\hline $\begin{array}{l}\text { Asia } \\
\text { woman }\end{array}$ & 0 & 1 & 2 & 6 & 0.0 & 4.3 & 3.6 & 13.3 & 0.036 & 0 & 1 & 1 & 9 & 0.0 & 4.3 & 1.8 & 19.6 & 0.006 \\
\hline Man & 20 & 22 & 54 & 39 & 100.0 & 95.7 & 96.4 & 86.7 & & 13 & 22 & 56 & 37 & 100.0 & 95.7 & 98.2 & 80.4 & \\
\hline $\begin{array}{l}\text { Aus/NZ } \\
\text { woman }\end{array}$ & 0 & 1 & 4 & 4 & 0.0 & 12.5 & 21.1 & 23.5 & 0.076 & 0 & 0 & 1 & 4 & 0.0 & 0.0 & 5.0 & 23.5 & 0.028 \\
\hline Man & 12 & 7 & 15 & 13 & 100.0 & 87.5 & 78.9 & 76.5 & & 10 & 8 & 19 & 13 & 100.0 & 100.0 & 95.0 & 76.5 & \\
\hline \multicolumn{19}{|l|}{$J B J S$} \\
\hline $\begin{array}{l}\text { All } \\
\text { woman }\end{array}$ & 3 & 15 & 52 & 40 & 2.0 & 9.6 & 13.0 & 16.1 & 0.00001 & 1 & 13 & 41 & 36 & 1.4 & 8.5 & 10.4 & 16.3 & 0.0003 \\
\hline $\begin{array}{l}\text { Man } \\
\text { North }\end{array}$ & 150 & 142 & 347 & 208 & 98.0 & 90.4 & 87.0 & 83.9 & & 68 & 140 & 352 & 185 & 98.6 & 91.5 & 89.6 & 83.7 & \\
\hline $\begin{array}{l}\text { America } \\
\text { woman }\end{array}$ & 3 & 14 & 42 & 27 & 2.3 & 10.2 & 14.0 & 15.3 & 0.00025 & 1 & 12 & 33 & 23 & 1.7 & 9.0 & 11.2 & 14.8 & 0.0052 \\
\hline Man & 127 & 123 & 258 & 150 & 97.7 & 89.8 & 86.0 & 84.7 & & 59 & 122 & 262 & 132 & 98.3 & 91.0 & 88.8 & 85.2 & \\
\hline $\begin{array}{l}\text { Europe } \\
\text { wman }\end{array}$ & 0 & 1 & 9 & 10 & 0.0 & 5.9 & 12.5 & 19.2 & 0.034 & 0 & 1 & 8 & 10 & 0.0 & 6.3 & 11.1 & 20.8 & 0.044 \\
\hline Man & 13 & 16 & 63 & 42 & 100.0 & 94.1 & 87.5 & 80.8 & & 6 & 15 & 64 & 38 & 100.0 & 93.8 & 88.9 & 79.2 & \\
\hline $\begin{array}{l}\text { Asia } \\
\text { woman }\end{array}$ & 0 & 0 & 0 & 1 & 0.0 & 0.0 & 0.0 & 7.1 & 0.27 & 0 & 0 & 0 & 2 & 0.0 & 0.0 & 0.0 & 15.4 & 0.10 \\
\hline Man & 8 & 2 & 25 & 13 & 100.0 & 100.0 & 100.0 & 92.9 & & 2 & 2 & 24 & 11 & 100.0 & 100.0 & 100.0 & 84.6 & \\
\hline \multicolumn{19}{|l|}{$B J J$} \\
\hline $\begin{array}{l}\text { All } \\
\text { woman }\end{array}$ & 8 & 17 & 22 & 38 & 6.3 & 10.1 & 8.4 & 15.5 & 0.01 & 8 & 13 & 17 & 38 & 6.2 & 7.5 & 6.2 & 15.4 & 0.003 \\
\hline Man & 118 & 151 & 239 & 207 & 93.7 & 89.9 & 91.6 & 84.5 & & 121 & 161 & 256 & 209 & 93.8 & 92.5 & 93.8 & 84.6 & \\
\hline
\end{tabular}


TABLE 4: Continued.

\begin{tabular}{|c|c|c|c|c|c|c|c|c|c|c|c|c|c|c|c|c|c|c|}
\hline & \multicolumn{9}{|c|}{ First author } & \multicolumn{9}{|c|}{ Corresponding author } \\
\hline & \multicolumn{4}{|c|}{$n$} & \multicolumn{4}{|c|}{$\% n$} & \multirow[b]{2}{*}{$p$ value $^{\wedge}$} & \multicolumn{5}{|c|}{$n$} & \multicolumn{2}{|c|}{$\% n$} & \multirow[b]{2}{*}{2016} & \multirow[b]{2}{*}{$p$ value $^{\wedge}$} \\
\hline & 1986 & 1996 & 2006 & 2016 & 1986 & 1996 & 2006 & 2016 & & 1986 & 1996 & 2006 & 2016 & 1986 & 1996 & 2006 & & \\
\hline North & & & & & & & & & & & & & & & & & & \\
\hline $\begin{array}{l}\text { America } \\
\text { woman }\end{array}$ & 2 & 0 & 4 & 4 & 15.4 & 0.0 & 13.8 & 6.3 & 0.60 & 2 & 0 & 3 & 7 & 15.4 & 0.0 & 9.7 & 10.9 & 0.72 \\
\hline Man & 11 & 18 & 25 & 60 & 84.6 & 100.0 & 86.2 & 93.8 & & 11 & 19 & 28 & 57 & 84.6 & 100.0 & 90.3 & 89.1 & \\
\hline $\begin{array}{l}\text { Europe } \\
\text { woman }\end{array}$ & 6 & 15 & 13 & 27 & 6.6 & 12.3 & 7.1 & 19.6 & 0.013 & 6 & 12 & 12 & 21 & 6.3 & 9.4 & 6.3 & 15.2 & 0.051 \\
\hline Man & 85 & 107 & 171 & 111 & 93.4 & 87.7 & 92.9 & 80.4 & & 90 & 115 & 179 & 117 & 93.8 & 90.6 & 93.7 & 84.8 & \\
\hline $\begin{array}{l}\text { Asia } \\
\text { woman }\end{array}$ & 0 & 1 & 2 & 5 & 0.0 & 4.8 & 6.5 & 16.1 & 0.06 & 0 & 1 & 1 & 7 & 0.0 & 4.8 & 3.0 & 21.2 & 0.015 \\
\hline Man & 12 & 20 & 29 & 26 & 100.0 & 95.2 & 93.5 & 83.9 & & 11 & 20 & 32 & 26 & 100.0 & 95.2 & 97.0 & 78.8 & \\
\hline $\begin{array}{l}\text { Aus/NZ } \\
\text { woman }\end{array}$ & 0 & 1 & 3 & 2 & 0.0 & 14.3 & 17.6 & 16.7 & 0.23 & 0 & 0 & 1 & 3 & 0.0 & 0.0 & 5.6 & 25.0 & 0.041 \\
\hline Man & 10 & 6 & 14 & 10 & 100.0 & 85.7 & 82.4 & 83.3 & & 9 & 7 & 17 & 9 & 100.0 & 100.0 & 94.4 & 75.0 & \\
\hline
\end{tabular}

Cochran linear trend test.

Aus/NZ = Australia/New Zealand.

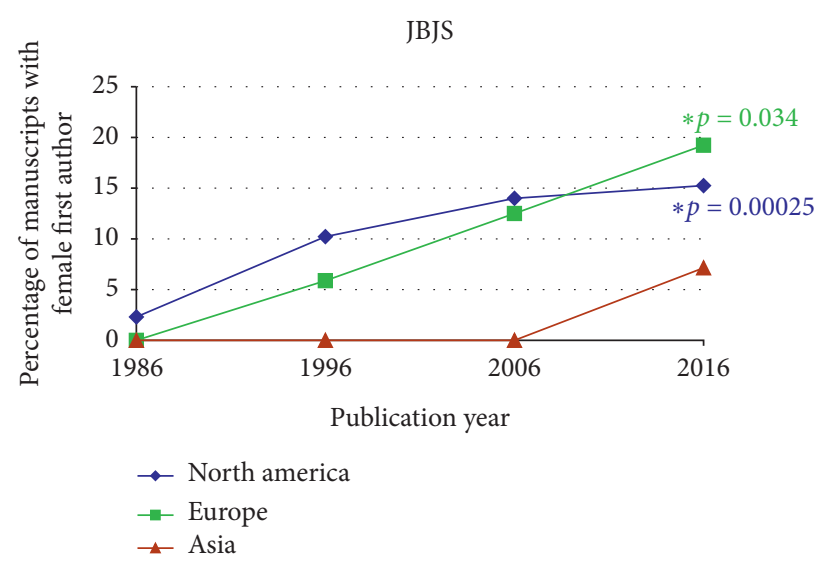

(a)

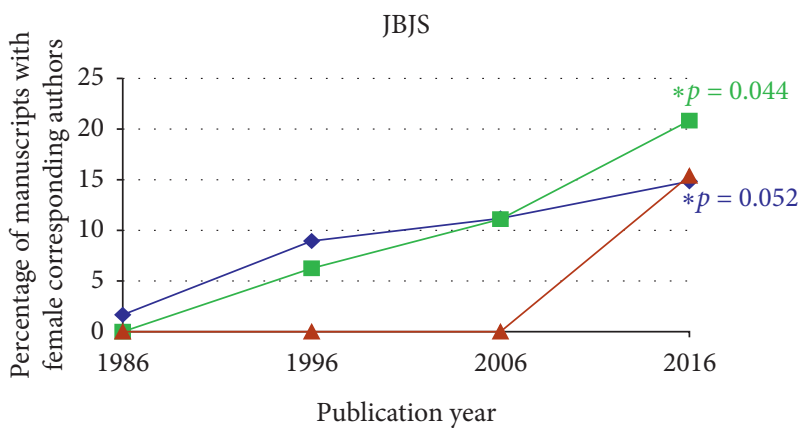

$\rightarrow$ North america
$\rightarrow$ Europe
$\rightarrow$ Asia

(c)

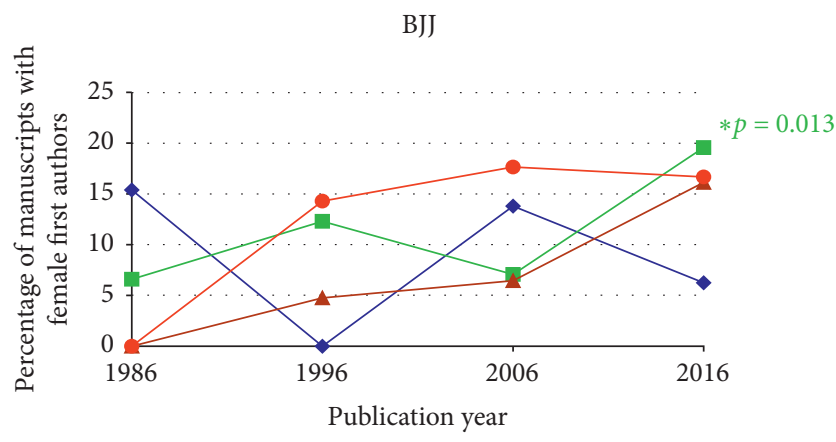

$\rightarrow$ North america $\rightarrow$ Asia

- Europe $\quad \rightarrow$ Australia/new zealand

(b)

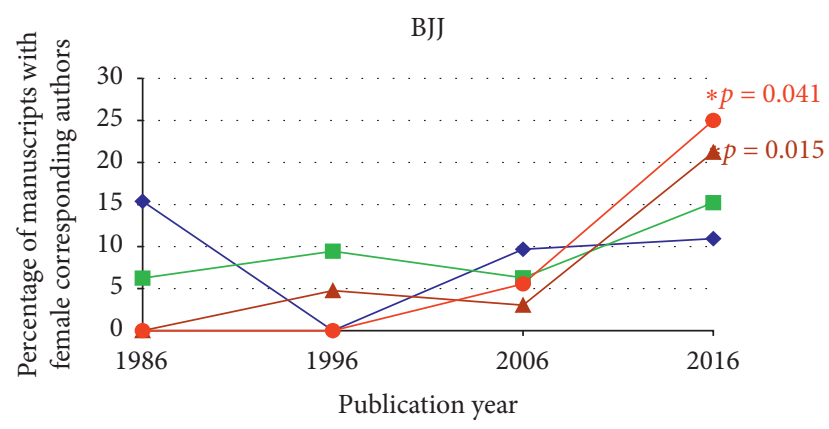

$\begin{array}{ll}\rightarrow-\text { North america } & \rightarrow \text { Asia } \\ \rightarrow-\text { Europe } & \rightarrow \text { Australia/new zealand }\end{array}$

(d)

FIgURE 3: Changes in the percentage of women as the first author for (a) JBJS and (b) BJJ and women as the corresponding author for (c) JBJS and (d) BJJ. The asterisks represent those having statistically significant changes over the four decades as assessed by the Cochran linear trend test.

gender combinations between journals (Figure 5(a)) $(p=0.80)$. There were significant differences over time for two gender combinations for JBJS (Figure 5(b)): WW $(p=0.023)$ and $\mathrm{MM}(p=0.013)$, but not WM $(p=0.10)$ or MW $(p=0.51)$. There were significant differences over time for two gender combinations for BJJ (Figure 5(c)): MW 


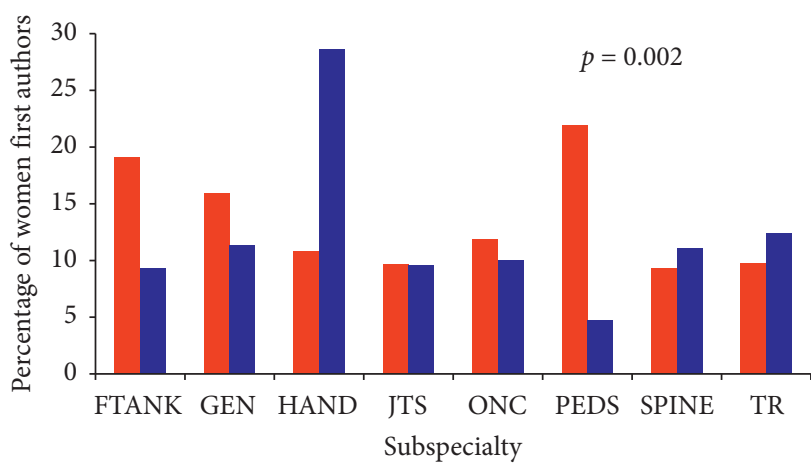

- JBJS

- $\mathrm{BJJ}$

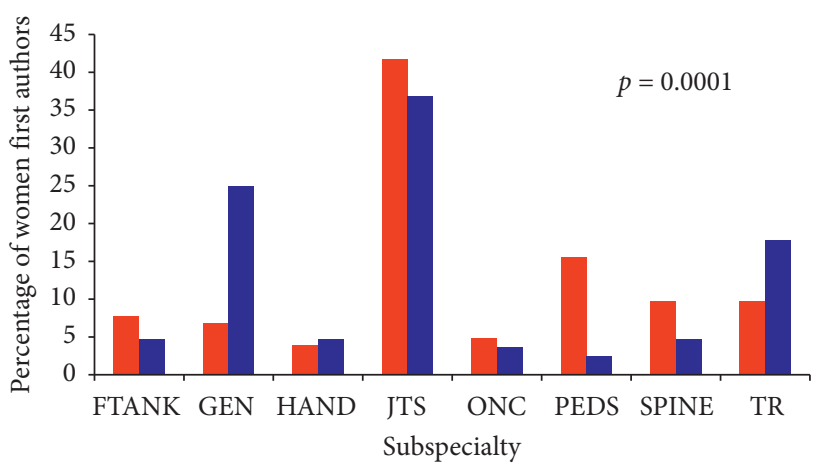

- JBJS

- BJJ

(a)

(b)

FIgURE 4: Percentage of women first authors across orthopedic subspecialties in JBJS and BJJ. Reporting percentages of women first authors relative to (a) the total number of manuscripts in a subspecialty and (b) the total number of manuscripts across all subspecialties. FTANK $=$ foot and ankle, GEN $=$ general, JTS $=$ joint arthroplasty, $\mathrm{ONC}=$ oncology, PEDS $=$ pediatrics, and $\mathrm{TR}=$ trauma.

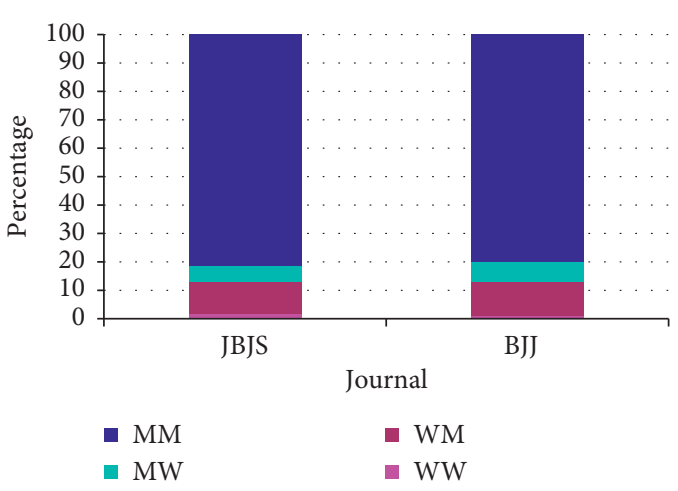

(a)

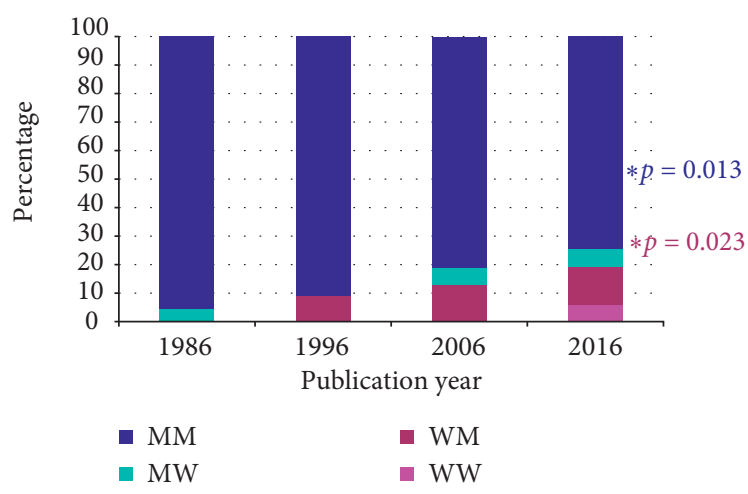

(b)

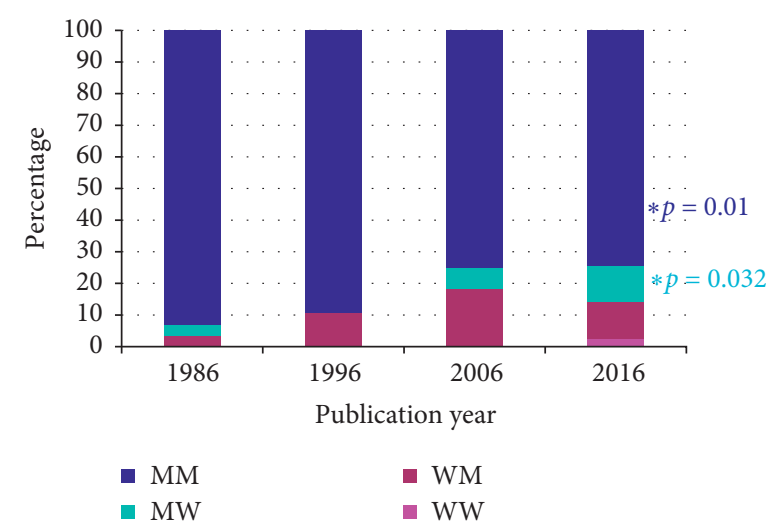

(c)

FIGURE 5: Gender combinations of first and corresponding authors for JBJS and BJJ. $M M=$ men as first and corresponding authors, $\mathrm{MW}=$ men as first and women as corresponding authors, $\mathrm{WM}=$ women as first and men as corresponding authors, WW= women as first and corresponding authors. (a) Between journals, (b) for JBJS, and (c) for BJJ. The asterisks represent those having statistically significant changes over the four decades as assessed by the Cochran linear trend test. 
$(p=0.032)$ and $\mathrm{MM}(p=0.01)$, but not WW $(p=0.15)$ or WM $(p=0.30)$.

\section{Discussion}

The number of authors, institutions, and countries collaborating on manuscripts published in both journals increased from 1986 to 2016. The increase in author number may be due to the need for individuals with different skill sets/expertise due to increasing research complexity [1-3]. Similar increases in author number have been reported across several musculoskeletal journals [17-26]. This increase may also be tied to the pressure for publication at all career levels $[7,34,35]$. Advances in technology and communication have made long-distance and intercountry collaborations more feasible [4]. The increase in collaboration seen over time in $J B J S$ and $B J J$ has likely also contributed to the increase in the number of citations $[1,36]$. The number of authors and pages in both JBJS and BJJ may decrease in the future, as both journals have implemented word and author number limits; 3000 words (excluding references) and no more than 6 authors for JBJS [37] and 4000 words (including references) and no more than 8 authors for BJJ [38]. However, throughout the time span of this study, there was a gradual increase in the number of references and authors for both $J B J S$ and $B J J$ and manuscript length for $B J J$.

The number of manuscripts published in both JBJS and $B J J$ increased from 1986 to 2006 before decreasing in 2016. The largest number of manuscripts for JBJS came from North America and for $B J J$ from Europe. This is expected as authors from North America would likely favor JBJS and European investigators $B J J$. It is not clear why the number of manuscripts in both journals increased up to 2006 and then dropped in 2016. Possible explanations are the increasing number of subspecialty journals as well as the introduction of several other journals under the umbrella of JBJS and BJJ.

One goal of this study was to examine the author's gender over time. In both journals, there was an increase in the percentage of women first and corresponding authors, but it was lower than the percentages of women US medical school graduates (50\%) [39] and women accepted to medical school in the UK (58\%) [40]. In 2013, in the US, women comprised $13.7 \%$ of orthopedic residents [41]. In 2016, women comprised only $6.5 \%$ of the American Academy of Orthopaedic Surgeons membership [42]. In 2014, in the UK, women comprised $25 \%$ of orthopedic trainees and $5 \%$ of orthopedic surgery consultants [15]. This may partly explain our findings regarding author gender.

We next began to explore possible mentorship trends and gender in authorship. To accomplish this, we used first and corresponding author gender composition ratios as a surrogate for mentorship, making the assumption that when first and corresponding authors were different individuals, the first author is the mentee of the corresponding author. With this in mind, WW gender combinations for first and corresponding authors increased in JBJS with time, and 2016 was also the first time that WW gender combinations were present in both JBJS and BJJ. This suggests an increase in the overall percentage of women, early in their careers, serving as the first author and being mentored by more senior women. This likely reflects the fact that over the last ten years women have now become President of the British Orthopaedic Association (2008), Royal College of Surgeons (2014), and American Academy of Orthopaedic Surgeons (2019). As women take on more leadership positions and mentor more junior women, the percentages of women first and corresponding authors will likely continue to increase. Another interesting observation was that while the overall gender combinations were the same between JBJS and BJJ, when looking at trends over time, there were significant differences. In both journals, MM combinations were reduced with time, but which categories were responsible for the reduction varied. For JBJS, there was a significant increase in the percentage of WW authors, whereas, for $B J J$, there was a significant increase in the percentage of MW authors. While not conclusively tested here, these findings may indicate that for JBJS, and the North American region by proxy, the increase in WW authors is likely a reflection of the increase in women orthopedic surgeons in the field, both at the more senior levels and at the trainee/junior levels. Perhaps, more interesting is the increase in MW combinations observed in $B J J$. There are a number of ways this data can be interpreted, but it may reflect a larger change in approach/attitude toward mentee/mentorship. This may suggest that for BJJ (and Europe by proxy), more junior men are seeking women as mentors or that women are seeking to serve as mentors to more men. This may be a positive sign that change is on the horizon when considering the gender gap in authorship.

Although there are fewer women orthopedic surgeons compared to men, studies have shown that women choose particular orthopedic subspecialties more than others $[43,44]$. In the current study, we found that the greatest percentage of manuscripts published by women was in joint arthroplasty. This is surprising as only $8.7 \%$ of women orthopedic surgeons in the USA select joint arthroplasty as their subspecialty [44]. The fact that joint arthroplasty manuscripts were the most common for women first authors in both journals may have several explanations. One explanation could be that joint arthroplasty may simply represent the subspecialty area with the greatest number of submitted/accepted manuscripts. Indeed, joint arthroplasty manuscripts accounted for $49 \%$ and $39 \%$ of all manuscripts published in the JBJS and BJJ during the years examined in the current study. Outside of joint arthroplasty, the greatest percentage of manuscripts with women as first authors was in pediatric orthopedics for JBJS and general for BJJ when considering women first authors across all subspecialties and in pediatric orthopedics and hand for JBJS and BJJ, respectively, when considering the total number of manuscripts in a particular subspecialty. This corroborates a 2016 survey of Ruth Jackson Orthopaedic Society women members which reported larger percentages of women surgeons listing hand $(22 \%)$ and pediatrics $(16 \%)$ as their subspecialty. In our study, the lowest percentage of manuscripts with women first authors for JBJS was the hand (3.9\%) and for BJJ was pediatrics (2.4\%) when considering women first authors across all subspecialties and the lowest were in the spine and pediatric orthopedics in JBJS and BJJ, 
respectively, when considering the total number of manuscripts in a particular subspecialty. While the finding in JBJS correlates with the 2016 survey reporting that women comprised the highest percentage of fellowship applicants for pediatrics (25\%), the BJJ finding that pediatric subspecialty manuscripts had few women first authors was surprising; this may reflect continental differences in subspecialty selection.

\section{Conclusion}

Manuscripts in JBJS and BJJ over the past 30 years have shown increases in the number of collaborating institutions, collaborating countries, references, and citations. The gender gap has decreased with the percentage of manuscripts with women first and/or corresponding authors increasing over the past 30 years.

\section{Data Availability}

The data are available from the corresponding author upon request.

\section{Conflicts of Interest}

The authors declare that there are no conflicts of interest.

\section{Authors' Contributions}

MAK, ECW, and RTL conceived and designed the study; MES, KS, DM, CM, DS, AMC, JCD, SMM, and CML collected and analyzed the data; RTL performed statistical analyses; MES, ECW, MAK, and RTL prepared the original manuscript; all authors participated in manuscript reviews and approved the final manuscript.

\section{Acknowledgments}

Elliott Beckner contributed to this work. This study was supported in part by The Department of Orthopaedic Surgery, Indiana University School of Medicine (MAK, RTL), the Ralph W. and Grace M. Showalter Research Trust (MAK), the Garceau Professorship Endowment and Rapp Pediatric Orthopaedic Research Fund, Riley Children's Foundation (RTL), and the Ruth Lilly Medical Library (ECW).

\section{References}

[1] J. M. Levitt and M. Thelwall, "Does the higher citation of collaborative research differ from region to region? A case study of Economics," Scientometrics, vol. 85, no. 1, pp. 171-183, 2010.

[2] S. Wuchty, B. F. Jones, and B. Uzzi, "The increasing dominance of teams in production of knowledge," Science, vol. 316, no. 5827, pp. 1036-1039, 2007.

[3] G. M. Olson, A. Zimmerman, and N. Bos, Scientific Collaboration on the Internet, The MIT Press, Cambridge, MA, USA, 2008.

[4] Science Europe and Elsevier's SciVal Analytics, Comparative Benchmarking of European and US Research Collaboration and Researcher Mobility, Science Europe, Brussels, Belgium, 2013.

[5] M. Angell, "Publish or perish: a proposal," Annals of Internal Medicine, vol. 104, no. 2, pp. 261-262, 1986.

[6] S. S. Hasan and K. Ahmadi, "Publish or perish," Academic Medicine, vol. 92, no. 2, p. 140, 2017.

[7] T. C. Erren, D. M. Shaw, and P. Morfeld, "Analyzing the publish-or-perish paradigm with game theory: the prisoner's dilemma and a possible escape," Science and Engineering Ethics, vol. 22, no. 5, pp. 1431-1446, 2016.

[8] R. A. Brumback, "3 . . 2 . . 1 . Impact [factor]: target [academic career] destroyed!" Journal of Child Neurology, vol. 27, no. 12, pp. 1565-1576, 2012.

[9] E. C. Halperin, "Publish or perish-and bankrupt the medical library while we're at it," Academic Medicine, vol. 74, no. 5, pp. 470-472, 1999.

[10] J. Parsonnet, P. A. Gruppuso, S. L. Kanter, and M. Boninger, "Required vs. elective research and in-depth scholarship programs in the medical student curriculum," Academic Medicine, vol. 85, no. 3, pp. 405-408, 2010.

[11] M. F. Griffin and S. Hindocha, "Publication practices of medical students at British medical schools: experience, attitudes and barriers to publish," Medical Teacher, vol. 33, no. 1, pp. e1-e8, 2011.

[12] American Association of Medical Colleges, Table B-1.2: Total Enrollment by U.S. Medical School and Sex, 2014-2015 through 2018-2019, American Association of Medical Colleges, Washington, NJ, USA, 2018, https:/www.aamc.org/ download/321526/data/factstableb1-2.pdf.

[13] S. Poon, D. Kiridly, M. Mutawakkil et al., "Current trends in sex, race, and ethnic diversity in orthopaedic surgery residency," Journal of the American Academy of Orthopaedic Surgeons, vol. 27, no. 16, pp. e725-e733, 2019.

[14] American Association of Medical Colleges, Figure 12. Percentage US medical school graduates by sex, academic years 1980-1981 through 2018-2019, 2020 https://www.aamc.org/data-reports/ workforce/interactive-data/figure-12-percentage-us-medical-scho ol-graduates-sex-academic-years-1980-1981-through-2018-2019.

[15] British Orthopaedic Trainees Association, Women in Surgery, British Orthopaedic Trainees Association, England, UK, 2018, http://www.bota.org.uk/women-in-surgery.

[16] The World Economic Forum, "The Global gender gap report," The World Economic, Cologny, Switzerland, 2020, https://www. weforum.org/reports/the-global-gender-gap-report-2017.

[17] A. E. Wininger, J. P. Fischer, E. F. Likine et al., "Bibliometric analysis of female authorship trends and collaboration dynamics OverJBMR's 30-year history," Journal of Bone and Mineral Research, vol. 32, no. 12, pp. 2405-2414, 2017.

[18] I. N. Aguilar, V. Ganesh, R. Mannfeld et al., "Authorship trends over the past 30-years in the Annals of biomedical engineering," Annals of Biomedical Engineering, vol. 47, no. 5, pp. 1171-1180, 2019.

[19] J. Dynako, G. W. Owens, R. T. Loder et al., "Bibliometric and authorship trends over a 30 year publication history in two representative US sports medicine journals," Heliyon, vol. 6, no. 3, pp. 1-10, Article ID e03698, 2020.

[20] F. Khan, M. M. Sandelski, J. D. Rytlewski et al., "Bibliometric analysis of authorship trends and collaboration dynamicsover the past three decades of BONE's publication history," Bone, vol. 107, no. 1, pp. 27-35, 2018.

[21] A. F. Russell, R. T. Loder, A. S. Gudeman et al., "A bibliometric study of authorship and collaboration trends over the past 30 years in four major musculoskeletal science journals," 
Calcified Tissue International, vol. 104, no. 3, pp. 239-250, 2019.

[22] A. F. Russell, M. Nguyen, M. Bhuiya et al., "Comparative analysis of bibliometric, authorship and collaboration trends over the past 30 year publication history of the Journal of Orthopaedic Trauma and Injury," Journal of Orthopaedic Trauma, vol. 32, no. 8, pp. e327-e333, 2018.

[23] A. R. Brinker, J. L. Liao, K. R. Kraus et al., "Bibliometric analysis of gender authorship trends and collaboration dynamics over 30 years of Spine 1985-2015," Spine, vol. 43, no. 14, pp. E849-E854, 2018.

[24] A. Seetharam, M. T. Ali, C. Y. Wang et al., "Authorship trends in the journal of orthopaedic research: a bibliometric analysis," Journal of Orthopaedic Research, vol. 36, no. 11, pp. 3071-3080, 2018.

[25] J. P. Fischer, A. E. Wininger, D. C. Scofield et al., "Historical analysis of bibliometric trends in the Journal of Pediatric Orthopaedics with a particular focus on sex," Journal of Pediatric Orthopaedics, vol. 38, no. 3, pp. e160-e171, 2018.

[26] A. W. Peters, M. K. Savaglio, Z. J. Gunderson et al., "Comparative analysis of authorship trends in the journal of hand surgery European and American volumes: a bibliometric analysis," Annals of Medicine and Surgery, vol. 55, pp. 200206, 2020.

[27] A. Gu, N. Almeida, J. S. Cohen, K. M. Peck, and G. A. Merrell, "Progression of authorship of scientific articles in the Journal of Hand Surgery, 1985-2015," Journal of Hand Surgery, American, vol. 42, no. 4, pp. 291.e1-291.e6, 2017.

[28] M. Mimouni, S. Zayit-Soudry, O. Segal et al., "Trends in authorship of articles in major ophthalmology journals by gender, 2002-2014," Ophthalmology, vol. 123, no. 8, pp. 1824-1828, 2016.

[29] H. A. Piwowar, "Who shares? Who doesn't? Factors associated with openly archiving raw research data," PLoS One, vol. 6, no. 7, pp. 1-13, Article ID e18657, 2011.

[30] S. Jehangir, E. H. Barnes, D. McDowell, and A. J. A. Holland, "Publishing trends in journal of paediatric surgery, pediatric surgery international and European journal of pediatric surgery over the past three decades," Pediatric Surgery International, vol. 35, no. 4, pp. 413-418, 2019.

[31] R. Lee, I. S. Mamidi, A. Gu, J. S. Cohen, W. Probasco, and J. DeBritz, "Current publication rates of abstracts presented at the Orthopaedic Trauma Association annual meetings 2005-2010," Journal of Orthopaedic Trauma, vol. 32, no. 5, pp. e171-e175, 2018.

[32] A. Leibbrandt and J. A. List, "Do women avoid salary negotiations? Evidence from a large-scale natural field experiment," Management Science, vol. 61, no. 9, pp. 2016-2024, 2015.

[33] G. Zhang, B. Demarest, and C. R. Sugimoto, "Gender and ethnicity trends in journal peer review: an empirical investigation using JASIST," Proceedings of the American Society for Information Science and Technology, vol. 49, no. 1, pp. 1-5, 2012.

[34] D. Rennie, V. Yank, and L. Emmanuel, "When authorship fails. A proposal to make contributors accountable," Journal of American Medical Association, vol. 278, no. 7, pp. 579-585, 1997.

[35] G. Tilak, V. Prasad, and A. B. Jena, "Authorship inflation in medical publications," Inquiry, vol. 52, Article ID 46958015598311, 2015.

[36] V. P. Guerrero Bote, C. Omeda-Gómez, and F. D. MoyaAnegón, "Quantifying the benefits of international scientific collaboration," Journal of the American Society for Information Science and Technology, vol. 64, no. 2, pp. 392-404, 2013.

[37] The Journal of Bone and Joint Surgery, 2020, https://journals. lww.com/jbjsjournal/Pages/Instructions-for-Authors.aspx.

[38] The Bone and Joint Journal. Manuscript Guidelines, 2020, https://online.boneandjoint.org.uk/bjj/information-for-authors.

[39] American Association of Medical Colleges, Table 12. U.S. Medical School Women Applicants, American Association of Medical Colleges, Washington, NJ, USA, 2016.

[40] The Royal College of Surgeons, Statistics-Women in Surgery, The Royal College of Surgeons, England, UK, 2018, https://www. rcseng.ac.uk/careers-in-surgery/women-in-surgery/statistics.

[41] S. E. Brotherton and S. I. Etzel, "Graduate medical education," Journal of American Medical Association, vol. 312, no. 22, pp. 2427-2445, 2014.

[42] AAOS Department of Research Quality and Scientific Affairs, Orthopaedic Practice in the US 2016, American Academy of Orthopaedic Surgeons, Rosemont, IL, USA, 2017.

[43] L. K. Cannada, "Women in orthopaedic fellowships: what is their match rate, and what specialties do they choose?" Clinical Orthopaedics and Related Research, vol. 474, no. 9, pp. 1957-1961, 2016.

[44] R. A. Bratescu, S. S. Gardner, J. M. Jones et al., "Which subspecialties do female orthopaedic surgeons choose and why? Identifying the role of mentorship and additional factors in subspecialty choice," JAAOS Global Research and Review, vol. 4, no. 1-5, Article ID e19.00140, 2020. 